\title{
Identification of the Causes of Deadline Slippage in Construction Projects: State of the Art and Application
}

\author{
Abdelhak Challal, Mohamed Tkiouat \\ Mohammadia School of Engineering Rabat, Studies and Research Laboratory in Applied Mathematics (LERMA), Mohammed V \\ University, Agdal, Maroc. \\ Email: challal@daag.finances.gov.ma,mohamedtkiouat@gmail.com
}

Received March 14 ${ }^{\text {th }}, 2012$; revised April 14 ${ }^{\text {th }}$, 2012; accepted April 20 ${ }^{\text {th }}, 2012$

\begin{abstract}
This study aims at analysing the causes assessment of deadline slippage in construction projects accomplished on the international level. It also identifies the said causes on the projects completed in Morocco in order to develop and put in place an adjusted modelling framework. The literature concerning this field has been examined during the last decade. A quantitative analysis of deadlines risks of sample of real estate project has been done in different regions of Morocco. This analysis has helped to identify and rank the delay causes while determining their frequency of occurrence their impact as well as their relative importance by combining two processes: macroscopic "Top-down" and microscopic "Bottom-down". In comparison with the previous research which was solely based on the first process, this method has specified an objective and exhaustive list of most causes. Three high-risk causes have been identified: the initial budget assessment, volatility of the architecture and engineering program and construction site hazards.
\end{abstract}

Keywords: Construction; Cause; Delays; Budget; Risk

\section{Introduction}

The problem of delays in the field of construction is a common phenomenon worldwide. In Saudi Arabia, AlAssaf and HHejji [1] found out that only $30 \%$ of construction projects have been completed within the contracted deadlines, and the average slipping period was between $10 \%$ and 30\%. In Nigeria, Ajanlekok [2] identified through a questionnaire survey the delays effects on 61 construction projects. The results demonstrated that deadline slippage and cost overruns were frequent and quite significant. The project manager is generally responsible for those causes. Odeyinka and Youssef [3] also illustrated that 7 projects out of 10 studied had experienced deadline slippage during their execution. Chan and Kumaraswamy [4] studied the delays in industrial construction in Hong Kong, they underlined the success index of a project and its delivery within the deadlines, respecting the quality norms and the budget allotted to it.

Normally, when we realise that the projects will experience some deadline slippage, we provide a deadline extension or we accelerate the pace of the works execution. As a consequence, we allow for additional expenses, normal practices which generally permit an addition of a supplementary cost percentage based on a prior study [5]. Time performance is one of the key measures of the project's success [5-8].
According to Faridi and El-Sayedgh [9] delays have a negative impact on the success of the project in terms of time, cost, quality and security For Aibium and Jagbor [10] the entrepreneur and the Project Manager are jointly or separately responsible for the delay in executing construction projects. The delays can not be minimised unless their causes are known, and in order to have an accurate estimate of costs and deadlines, reliable methods and commonly agreed practices must be applied. Faridi and El-Sayedgh also emphasised that these causes must be controlled during the life time of the project. Moreover, an important economy of resources can be obtained while identifying and controlling the causes.

The main objectives of this study are as follows.

- Identifying the causes of delays in construction projects in several regions of Morocco as well as comparing them with those identified by researchers in over the last two decades;

- Ranking the inherent risks in terms of the probability and importance perceived by the participants, such as, the project manager ,the clients and the contractors;

- Identifying risks control measures.

This article is organised as follows: section 1 deals with the previous studies on the causes of deadline slippage in construction projects. Section 2 explains the methodology adopted its limitations and acquisitions. Sec- 
tion 3 discusses the results. Section 4 presents the actions and measures which minimise construction project delays Section 5 attempts to draw conclusions and perspectives.

\section{Literrature Review}

Many articles and studies conducted on the causes of construction project delays worldwide have been examined. Ubaid [11] concluded in his surveys on the projects completed in Saudi Arabia that lack of entrepreneurial performance is one of the major causes of delays. He also identified the principle measures to reinforce re-sources and improve entrepreneurial skills. Assaf, Al-K et al. [12] Ghafly observed that the major causes linked to construction projects in Saudi Arabia are due to financial problems, changes in project conception, projects' contributions, delay in decisions-taking, getting owners approval, difficulties in getting a work permit, communication and coordination problems. Chan and Kumaraswamy [13] have carried out a survey to evaluate the relative importance of 83 factors of potential delays in construction projects in Hong Kong. They observed that 5 major causes of deadline slippage related to mismanagement of risk, bad supervision, condition of the site, delay in taking decisions, varying customer needs, variation of working time. Kaming et al. [14] has studied the causes of slippage of the completion date of 31 skyscrappers in Indonesia He noticed that cost overruns happen most frequently and are most significant than deadline slippage. He underlined that the main causes of this slippage are: the increase due to inflation, the underestimate of material cost as well as the degree of complexity of the construction project itself, those relating to slippage are: change of design conception, weak productivity, inadequate planning, shortage of resources. Kumaraswamy and Chan noted in a study that the causes in construction projects conducted in Honk Kong that there were differing perceptions by the different parties. Noulmanee et al. [15] concluded in a study on the causes of delays in the construction of highways in Tahaland that the major causes are due to sub-contractors' incompetency and poor project conception (incomplete and inaccurate design) They also suggested that the delay could be minimised by devising a good project conception, close coordination and an effective communication among between the participants. Al-Momani [16] in his survey on 130 public projects in Jordan pointed out that the main causes of delay are: poor project conception, climate, poor site management, delay in delivery, economic situation and the amendments. He recommended that managers of public projects take the necessary time to start carrying out thorough studies by using real quan- titative data in order to formulate pertinent terms before starting attributing the said project. The study also suggested that special attention be given to industrialists in the field of construction to reduce the purchasing costs. Consequently, the delays are essentially due to poor contracters productivity According to (Koushk et al., Assaf SA and d'Al-Hajji, Meeampol and Ogunlana LO [17], Sambasivan M and YW. Soon [18], Le-Hoai et al. [19] deadline slippage could lead to a number of negative effects, such as cost overruns Sambasivan and Soon, Towhid and Amiruddin [20] noted that major delay consequences are related to: arbitration conflicts, litigations, and total abandonment. Toor and S. O. Ogunlana [21] and Saleh Al Hadi Tumi et al. [22] believe that poor planning and lack of communication are the principle causes of deadline slippage in construction projects in Libya. Hamidreza et al. [23] qualified certain causes as unacceptable in order to respect the contractual deadline for the completion of the construction projects in Hong Kong. These causes are relative to delays of supply and subcontractors' incompetence. M. Haseeb1 et al. [24] consider that to avoid delays, the project manager must settle the corporate discount on time. Also the enterprise must do the same thing for the subcontractors. Ogunlana et al. [25] noticed that time and cost overruns in construction projects of sky-scrappers in Bankok and Thailand resulted from three factors: lack of infrastructure, default in payment by both customers and consultants, and contractors incompetency, they recommended that managers and associations specicilising in the field of construction make more efforts to streamline and build the infrastructure which would allow easy supply of materials and boost efficiency in the field of construction. Frimpong et al. [26] conducted a survey through a questionnaire on underground construction projects in Ghana in order to identify and evaluate the importance related to the factors leading to time and cost overruns of the said projects. The findings revealed that the main causes are: late payment on the part of the project managers, shortage of raw materials, implementation of obsolete construction processes, and the high cost of raw materials. They recommended that to minimise the delays in carrying out the construction works, the projects should be well in advance, and a follow-up must be insured as well as the control and respect of the accomplishment planning.

Over the last decade, researchers have looked into the causes and effects of delays in construction projects and confirm that $51 \%$ of the responsibility lies with the enterprises, followed by the project manager $30 \%$ and the client $19 \%$ and that $90 \%$ of these causes arise from the field and the internal organisation of the intervening parties.

Also the researchers have shown that the causes which 
occur frequently can be summarised as follows:

- Poor management of the site;

- The company's financial difficulties;

- Modifications made by the employer during the construction phase;

- Delay in plan examination and approval by the project manager;

- Delay in issuing plans.

\section{Methodology Adopted: Limitations and Skills}

According to the "top-down" process adopted so far by the previous so-called macroscopic studies, and which helped to investigate and assess major risks on the macroprocess through documentary research, interviews, questionnaires, by starting the evaluation of frequent occurrences the severity and importance related to the causes by the contractors, the project manager, and the owners. These risks were ranked according to the retained criteria leading to the establishment of a mapping of risk causes.

Also, 13 major causes were identified 9 of which resulted from lack of both organisation and mastery of operations; 7 causes were foreign or partially to the organisation of the operation (see Figure 1).

The top-down approach certainly helps dispose of a risks mapping in a short time. However, this approach was criticised for being very synthetic and more subjective, given that it was not achieved by the actors in the field in reference to their daily activities; still it helped to hold a limited number of people in charge (Management and responsible for bid processes). Hence, a quick identification and assessment of perceived risks. On the other hand, the top-down approach does not help identify and analyse the risks on the process and sub-process related to the management activities of deadlines and costs, nor does it help identify the control points as well as the measures helping to master the risks. This demonstrates therefore an organisational short-sightedness according to which the different participants could not see beyond the covered fields. It is not from this point of view that a bottom-up approach to analyse the risks related to deadline management takes its full meaning

\subsection{Top-Down Approach}

\subsubsection{Limitations}

The methodological elements used were inspired from the best practices and adapted to the context and level of maturity of the enterprises, the project manager and owners; as such it would help generate a mapping of causes and risks.

However, the success and efficiency of mapping the causes of deadline slippage is based on the ability of the enterprises, the project manger and the owners to put them into good effect. Nevertheless, these rules are reinterpreted according to the case and the objectives of those involved. The methodological elements must be considered as a dynamic base to be continually enriched by the participants on the basis of the specificities of their environments and the evolution of these environments in time.

\subsubsection{Reference Methodology of Overruns Causes Mapping}

\subsubsection{Definition of a Common Language}

One of the first actions that have been conducted during the initiation stage to practicing the mapping of causes of deadline slippage is to ascertain the existence of a framework which is clear and known to all.

This framework goes through the definition of a common language:

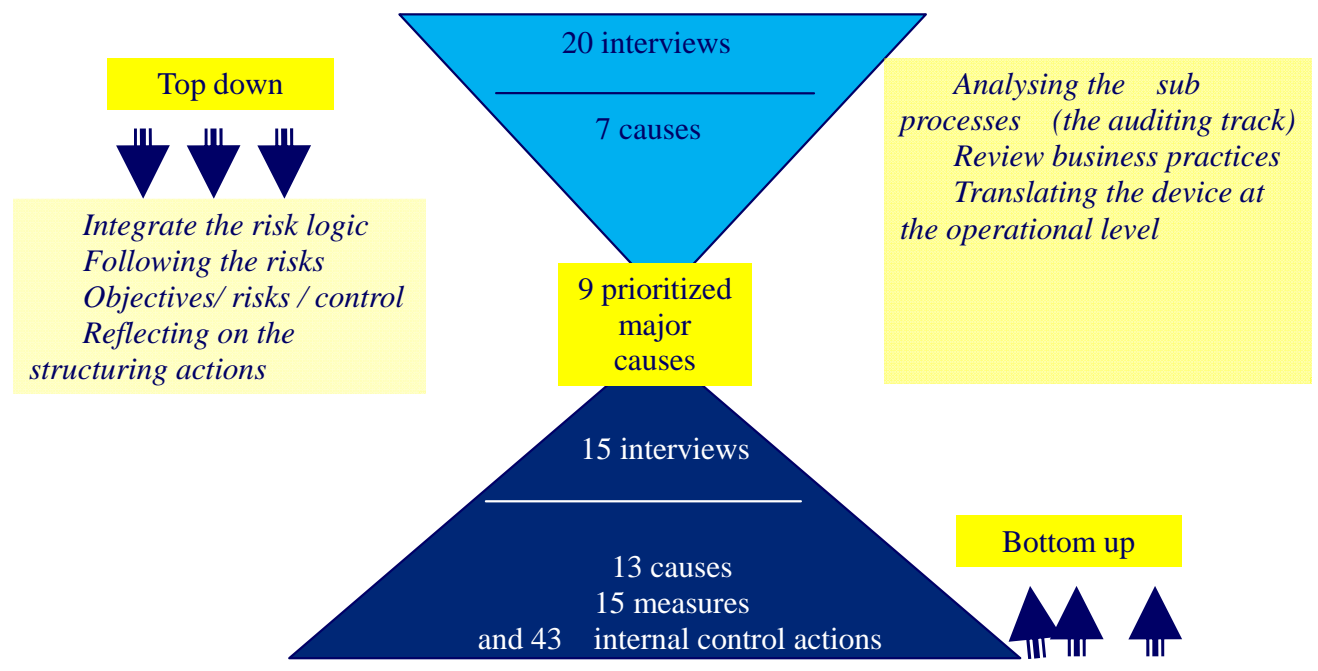

Figure 1. Top-down and Bottom-up process. 
So, the grids of reference that helped reconcile these requirements are as Grids A1-A3.

\subsubsection{Conduct of Interviews}

It is one of the key-stages of the process. The interviews are supposed to bring out the participants' maximum added-value.

The main objective is to collect the participants' vision and perception concerning the most critical causes of deadline slippage, the key measures that should be taken or could minimise the risk causes identified.

\subsubsection{Formalisation and Validation of the List of Major Risks}

Once the interviewing stage finished, an inventory of all the causes of deadline slippage has been carried out so that they should be reprocessed them again, synthesised and regrouped them into a family of causes called "grouped" or "major". This stage is essential as it will help to work on these causes in a structured and more efficient way, while establishing the link between the practical field-related issues raised by the participants in the questionnaire or during the interviews, pointing out

\begin{tabular}{cc}
\hline & Probability \\
\hline Level 1 & Rare or very rare \\
Level 2 & Regular/frequent \\
Level 3 & Very frequent to systematic \\
\hline
\end{tabular}

Grid A1. A summary of probability and assessment of risks.

\begin{tabular}{cc}
\hline \multicolumn{2}{c}{ Impact } \\
\hline Level 1 & Weak $(0-4)$ \\
Level 2 & Moderate $(4-7)$ \\
Level 3 & Strong $(7-10)$ \\
\hline
\end{tabular}

Grid A2. A summary of assessment of potential risk impact.

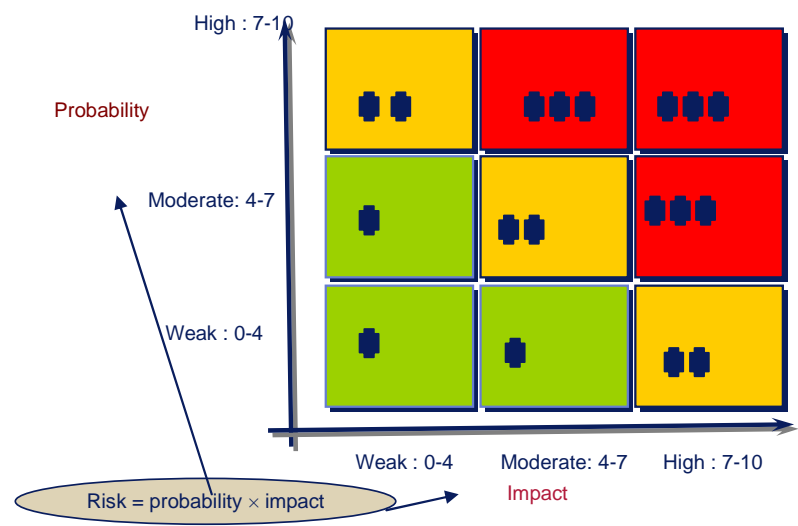

Grid A3. A summary of severity evaluation. the consequences of the potential risks on the participants objectives. The number of causes of major risks could basically vary from one mapping process to another. Hence, nevertheless a good practice is set between the ranges of 5 to 25 .

\subsubsection{Ranking of Risks}

A number of workshops on ranking of risks have been held (one or several participants by category). These workshops constituted the "object" of the process as the participants will express their views on the assessment of each major risk. It should be noted, however, that such a workshop is not based on a "scientific" or statistical analysis of risks, but on the different participants' perception of risk. Hence the crucial nature of the "casting" stage previously mentioned. Participants must be clearly reminded that by nature they generally tend to base their evaluation on tangible data and figures. Besides, if for some risks the participants use a "basis" listing all the incidents which have occurred ("recognised" risks) the latter could be taken account of as a need on this level of perception, notably as far as the criterion of the probability of occurrence is concerned.

From a practical point of view, the workshop lasted generally half a day; each risk was voted for by a show of hands using each of the two criteria (impact and probability of occurrence) and by answering the following questions:

- Who evaluates the impact on a weak level?

- Who evaluates the impact on a moderate level?

- Who evaluates the impact on a high level?

The same questions have then been posed concerning the probability criterion.

The results have been counted for each risk simultaneously.

A quick counting of the average vote on each criterion has helped to position the risk concerned on the mapping on the basis of the "marking" explained for these two criteria.

\subsubsection{Mapping Formalization}

Beyond the mapping itself (a graph composed of two axes: impact and probability) it is always important to analyse the votes by way of statistics (of average impact and probability, variances measuring the scattering of votes on a particular risk/a given criterion, etc.).

\subsection{Bottom-Up Process}

This process consisted in analysing the deadline process related to deadline management of a construction project, in such a way as to identify the inherent risks, determine their significance and finally the control policy of each of these risks. 
Finally, in order to determine a complete list of the said causes as well as the actions and measures of control, we have combined both steps so that it would be more objective and comprehensive.

\section{The Research Findings}

\subsection{The General Characteristics of the Respondents}

The infield survey conducted consisted of 15 contractors, 9 project managers, and 9 owners. 13 deadline slippage causes were identified during the research, and actions and control measures were studied.

$55 \%$ of the contractors, $80 \%$ of the project managers and $70 \%$ of the clients indicated the average slippage was somewhere between $10 \%$ and $30 \%$ of the initial period for $70 \%$ of the projects, and that the real costs were different from the initial estimates in $95 \%$ of the cases.

\subsection{Ranking the Delay Causes Using the Ishikawa Diagram}

The Ishikawa Diagram, also known as the cause-effect diagram is a tool to systematically present the possible causes of a particular problem in a graph. These problems are presented on two detailed and different levels in the fish bone diagram. The top case of the diagram contains the presentation of the problem (see Diagram A1).

\subsubsection{Frequency of Delay Causes}

The most frequent causes are related to insufficiency or absence of prior studies and feasibility of the projects, errors made in the initial budget assessment errors arrangement, errors of piloting and coordination in the study phase and during the construction period, volatility in the architecture and engineering program (multiple modification requests) external delay procedures (granting subsidies, issuing construction permits etc.) failure of some participant, working site hazards as mentioned in Table A1.

\subsubsection{Severity of Delay Causes}

The most serious deadline slippages are due to a number of causes, namely errors in the estimate of the initial budget, lack of concentration, volatility in the architecture and engineering program, delay in external procedures, hazards in working site, and the failure of some actor as mentioned in Grid A4.

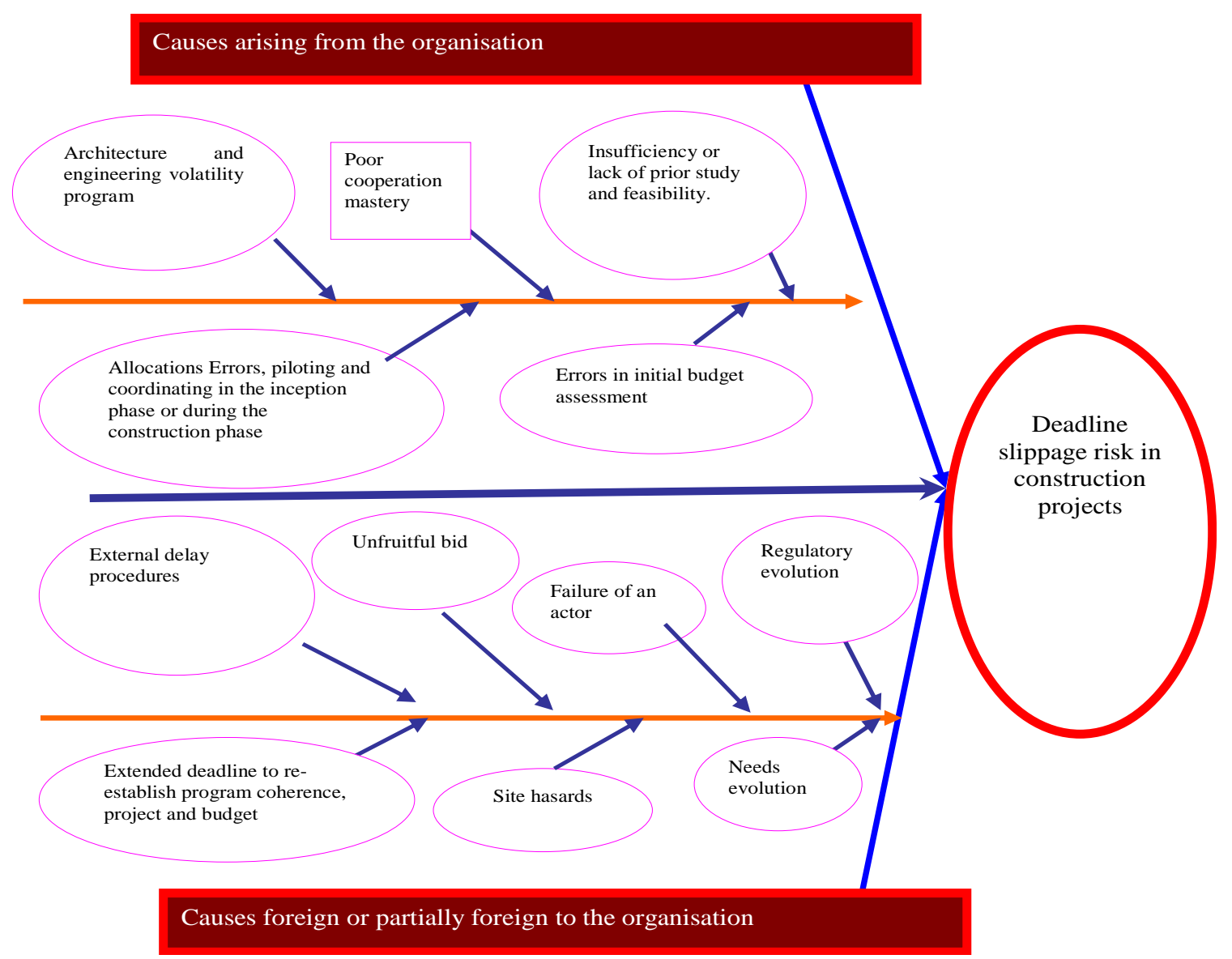

Diagram A1. The Ishikawa diagram. 
Table A1. Frequency, impact, criticality of causes.

\begin{tabular}{|c|c|c|c|c|c|}
\hline Category & Ref & Risk causes & Probability & Impact & Criticality* \\
\hline \multirow{6}{*}{$\begin{array}{l}\text { Causes arising from } \\
\text { the organisation }\end{array}$} & CR2 & $\begin{array}{l}\text { Architecture and engineering volatility program } \\
\text { (multiple modification requests) }\end{array}$ & 9 & 8 & 72 \\
\hline & CR7 & Poor cooperation mastery & 5 & 9 & 45 \\
\hline & CR7’ & Allocation errors ,piloting and coordinating in the inception phase & 9 & 5 & 45 \\
\hline & CR7” & Allocation errors, piloting during the construction phase & 9 & 5 & 45 \\
\hline & CR5 & Insufficiency or lack of prior study and feasibility & 10 & 5 & 50 \\
\hline & CR1 & Errors in initial budget assessment/allocation & 10 & 10 & 100 \\
\hline \multirow{7}{*}{$\begin{array}{l}\text { Causes foreign or partially } \\
\text { foreign to the organisation }\end{array}$} & CR6 & $\begin{array}{l}\text { External delay procedures } \\
\text { (allocating of subsidies, issuing construction permit, etc.) }\end{array}$ & 8 & 6 & 48 \\
\hline & CR8 & $\begin{array}{l}\text { Extended deadline to re-establish program } \\
\text { coherence, project and budget }\end{array}$ & 6 & 6 & 36 \\
\hline & CR10 & Unfruitful bid & 5 & 3 & 15 \\
\hline & CR4 & Failure of an actor & 8 & 7 & 56 \\
\hline & CR3 & Site hazards & 8 & 8 & 64 \\
\hline & CR11 & Regulatory evolution & 3 & 1 & 3 \\
\hline & CR9 & Needs evolution & 6 & 3 & 18 \\
\hline
\end{tabular}

* Probability $\times$ Impact.

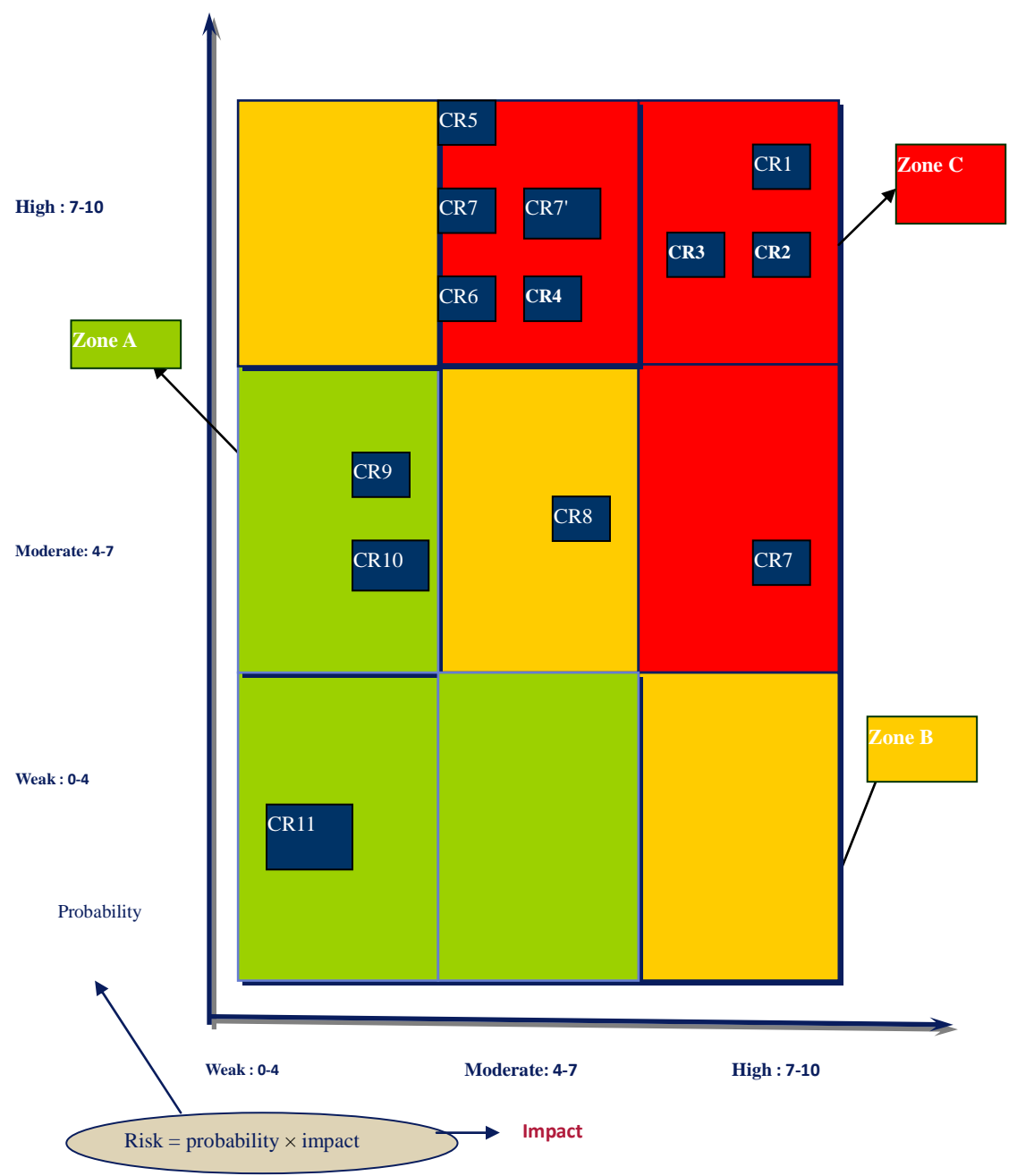

Grid A4. Reference of the criticality assessment risk. 
According to the grid reference of the criticality risk assessment below, 9 risks have been found in zone C (a high-risk zone), 1 risk in zone B (moderate risk zone), the remaining risks have been found in zone A (a weakrisk zone).

From now on the risks that have been retained are found in zone $\mathrm{C}$, given the importance of their criticality on the objectives set for the construction projects;

It has also been observed that after analysing the results of the interviews with the different intervening parties most causes lie with the project manager 56\% the client $44 \%$; the internal causes are related to the scope of organisation where control of operation accounts for $67 \%$ against $33 \%$ of external causes.

\subsubsection{Importance of Rank Correlation}

Spearman's coefficient rank correlation is used to measure the degree of agreement and disagreement associated with the importance of each party rank. Equation (1) for that purpose.

\subsubsection{Data Analysis Methode}

The method used to analyse data is the relative importance index method. This index quantifies the relative importance of diverse delay causes following the experts' hindsight judgements. It is calculated as follows:

Equation (A.1): relative importance index.

$$
\operatorname{IIR}=\frac{\sum_{i=1}^{i=A} n_{i} \times i}{A \times N}
$$

Or

$n_{i}$ : the number of respondents having given an importance of $i$ to the factor in question.

$A$ : the highest importance that is 5 in our case.

$N$ : the total number of respondents.

This relative importance index varies between 0 and
1 (0 excluded). Plus IIR is high, plus this factor contributes largely to project delays.

The choice of the number of experts to have been interviewed was limited to 10 , including architects, contractors, project mangers, owners with great experience in construction projects.

\subsubsection{Results Analysis}

The relative importance indexes have been calculated for each factor to estimate contribution rates of each delay in construction projects.

The Table A2 transmits the data collected, as such there is cause that the ranks obtained through the relative importance method are similar to those obtained by the impact and probability evaluation criteria.

\section{Conclusions and Perspectives}

Even though a lot of works have already been undertaken abroad, we believe that this type of work is the first of its kind which combines both the Top-down macroscopic process and the Bottom-down microscopic one.

Indeed we have been able to make the list of deadline slippage exhaustive in project constructions:

- By identifying all deadline slippage causes through analysing and breaking down the processes;

- By approaching the most through interviews, those in charge of the implementation process.

Thus, this work helps bring out to light the importance of taking account of time overrun risks during the preliminary design stage of construction projects. The uncertainties the duration of the projects tasks of construction have been explained by the delay causes which have been identified and ranked in terms of importance such as:

- Causes arising from organisation or control of operation.

Table A2. A comparative ranking of causes through the relative importance method and the criticality evaluation method.

\begin{tabular}{|c|c|c|c|c|c|c|c|}
\hline Ref & Risk causes & Probability & Impact & Criticality & Rank & IIR & Rank \\
\hline CR1 & Errors in initial budget assessment & 10 & 10 & 100 & 1 & 0.9 & 1 \\
\hline CR3 & Site hazards & 8 & 8 & 64 & 3 & 0.78 & 3 \\
\hline CR5 & Insufficiency or lack of prior study and feasibility. & 10 & 5 & 50 & 5 & 0.65 & 5 \\
\hline CR6 & $\begin{array}{l}\text { External delay procedures } \\
\text { (allocating of subsidies, issuing construction permit etc.) }\end{array}$ & 8 & 6 & 48 & 6 & 0.57 & 6 \\
\hline CR7 & Poor cooperation mastery & 5 & 9 & 45 & 7 & 0.42 & 7 \\
\hline CR7' & Allocations Errors, piloting and coordinating in the inception phase & 9 & 5 & 45 & $7^{\prime}$ & 0.42 & $7^{\prime}$ \\
\hline CR7” & Allocation errors, piloting during the construction phase & 9 & 5 & 45 & 7’’ & 0.42 & 7’' \\
\hline
\end{tabular}


CR 1: Errors in the estimate of the initial budget;

CR 2: Volatility of the architecture and engineering program (multiples modifications requests);

CR 6: Poorly controlled coordination;

CR 6': Errors in scheduling, in piloting and coordination during the stage of study phase;

CR 6": Errors in scheduling, in piloting and coordination during the construction stage;

CR 5: Insufficiency or lack of prior studies and their feasibility.

- Foreign causes or partially foreign to the organisation of the operation.

CR 7: Extended deadline to restore coherence to the budget project;

CR 4: Failure of some actor;

CR 3: Working site hazards.

\section{REFERENCES}

[1] S. A. Assaf and S. Al-Hejji, "Causes of Delay in Large Construction Projects,” International Journal of Project Management, Vol. 24, 2006, pp. 349-357.

[2] J. O. Ajanlekoko, "Controlling Cost in the Construction Industry,” Lagos QS Digest, Vol. 1, No. 1, 1987, pp. 812.

[3] H. A. Odeyinka and A. Yusif, “The Causes and Effects of Construction Delays on Completion Cost of Housing Projects in Nigeria," Journal of Financial Management of Property and Construction, Vol. 2, No. 3, 1997, pp. 3144.

[4] D. W. Chan and M. M. Kumaraswamy, "A Comparative Study of Causes of Time Overruns in Hong Kong Construction Projects," International Journal of Project Management, Vol. 15, No. 1, 1997, pp. 55-63. doi:10.1016/S0263-7863(96)00039-7

[5] Z. Hatush and M. Skitmore, "Evaluating Contractor Prequalification Data: Selection Criteria and Project Success Factors," Construction Management and Economics, Vol. 15, No. 2, 1997, pp. 129-147. doi:10.1080/01446199700000002

[6] W. Belassi and O. I. Tukel, "A New Framework for Determining Critical Success/Failure Factors in Projects," International Journal of Project Management, Vol. 14, No. 3, 1996, pp. 141-151. doi:10.1016/0263-7863(95)00064-X

[7] D. H. T. Walker, "An Investigation into Construction Time Performance”, Construction Management and Economics, Vol. 13, No. 3, 1995, pp. 263-274. doi:10.1080/01446199500000030

[8] D. H. T. Walker, "The Contribution of the Construction Management Team to good Construction Time Performance-An Australian Experience," Journal of Construction Procurement, Vol. 2, No. 2, 1996, pp. 4-18.

[9] A. S. Faridi and S. M. El-Sayegh, "Significant Factors Causing Delay in the UAE Construction Industry," Construction Management and Economics, Vol. 24, No. 11, 2006, pp. 1167-1176. doi:10.1080/01446190600827033
[10] A. A. Albinu and G. O. Jagboro, "The Effects of Construction Delays on Project Delivery in Nigerian Construction Industry,” International Journal of Project Management, Vol. 20, 2002, pp. 593-599.

[11] A. G. Ubaid, "Factors Affecting Contractor Performance," Master's Thesis, King Fahd University of Petroleum and Minerals, Dhahran, 1991.

[12] S. A. Assaf, M. Al-Khalil and M. Al-Hazmi, "Causes of Delays in Large Building Construction Projects,” Journal of Management in Engineering, Vol. 11, No. 2, 1995, pp. 45-50. doi:10.1061/(ASCE)0742-597X(1995)11:2(45)

[13] M. Kumaraswamy and D. Chan, "Contributors to Construction Delay," Construction Management and Economics, Vol. 16, No. 1, 1998, pp. 17-29. doi:10.1080/014461998372556

[14] P. Kaming, P. Olomolaiye, G. Holt and F. Harris, "Factors Influencing Construction Time and Cost Overruns on High-Rise Projects in Indonesia,” Construction Management and Economics, Vol. 15, No. 1, 1997, pp. 83-94. doi:10.1080/014461997373132

[15] A. Noulmanee, J. Wachirathamrojn, P. Tantichattanont and P. Sittivijan, "Internal Causes of Delays in Highway Construction Projects in Thailand," 1999. www.ait.c1et.com

[16] A. H. Al-Momani, "Construction Delay: A Quantitative Analysis,” International Journal of Project Management, Vol. 18, No. 1, 2000, pp. 51-59. doi:10.1016/S0263-7863(98)00060-X

[17] S. Meeampol and S. O. Ogunlana, "Factors Affecting Cost and Time Performance on Highway Construction Projects: Evidence from Thailand," Journal of Financial Management of Property and Construction, Vol. 11, No. 1, 2006, pp. 3-20. doi:10.1108/13664380680001076

[18] M. Sambasivan and Y. W. Soon, "Causes and Effects of Delays in Malaysian Construction Industry," International Journal of Project Management, Vol. 25, 2007, pp. 517526.

[19] L. Le-Hoai, Y. D. Lee and J. Y. Lee, "Delay and Cost Overruns in Vietnam Large Construction Projects: A Comparison with Other Selected Countries," Journal of Civil Engineering, Vol. 12, No. 6, 2008, pp. 367-377.

[20] T. Pourrostam and A. Ismail, "Significant Factors Causing and Effects of Delay in Iranian Construction Projects,” Australian Journal of Basic and Applied Sciences, Vol. 5, No. 7, 2011, pp. 450-456.

[21] S. U. R. Toor and S. O. Ogunlana, "Problems Causing Delay in Major Construction Projects in Thailand," Construction Management and Economics, Vol. 26, No. 4, 2008, pp. 395-408. doi:10.1080/01446190801905406

[22] S. Al H. Tumi, A. Omran and A. H. K. Pakir, "Causes of Delay in Construction Industry in Libya,” The International Conference on Economics and Administration, Faculty of Administration and Business, Bucharest, 14-15 November 2009, pp. 265-272.

[23] H. Afshari, S. Khosravi, A. Ghorbanali, M. Borzabadi and M. Valipour, "Identification of Causes of Non-Excusable Delays of Construction Projects,” International Conference on E-Business Management and Economics, 
Hong Kong, 28-30 December 2010, pp. 42-46.

[24] M. Haseeb, X. H. Lu, A. Bibi, Maloof-ud-Dyian, W. Rabbani, "Causes and Effects of Delays in Large Construction Projects of Pakistan," Kuwait Chapter of Arabian Journal of Business and Management Review, Vol. 1, No. 4, 2011, pp. 18-42.

[25] S. O. Ogunlana, K. Promkuntong and V. Jearkjirm, "Construction Delays in a Fast-Growing Economy: Comparing
Thailand with Other Economies,” International Journal of Project Management, Vol. 14, No. 1, 1996, pp. 37-45. doi:10.1016/0263-7863(95)00052-6

[26] Y. Frimponga, J. Oluwoyeb and L. Crawfordc, "Causes of Delay and Cost Overruns in Construction of Groundwater Projects in a Developing Countries, Ghana as a Case Study," International Journal of Project Management, Vol. 21, No. 5, 2003, pp. 321-326. 